\title{
The novel acceptor splice site mutation $11396(G \rightarrow A)$ in the factor XII gene causes a truncated transcript in cross-reacting material negative patients
}

\author{
Manfred Schloesser*, Sigrun Hofferbert, Ute Bartz, Gerd Lutze ${ }^{1}$, Bernhard Lämmle ${ }^{2}$ and Wolfgang Engel \\ Institut für Humangenetik der Universität Göttingen, D-37073 Göttingen, 'Institut für Klinische Chemie der Universität Magdeburg, D-39120 \\ Magdeburg, Germany and ${ }^{2}$ Hämatologisches Zentrallabor, Universitätsspital Bern, $\mathrm{CH}-3010$ Bern, Switzerland
}

Received December 21, 1994; Revised and Accepted April 19, 1995

Factor XII (Hageman factor) is an important element in several plasma protease cascades such as the blood coagulation system, the kinin system and fibrinolysis (1). Homozygous factor XII deficiency with no enzymatic activity is thought to result in a slightly increased risk of venous thromboembolism, but placental thrombosis, myocardial infarction and other thrombotic complications have been reported in some patients $(2,3)$. The factor XII protein has the typical features of a member of the serine protease family with the active site residues encoded by the terminal exons 10-14 (4). To date only a few sequence alterations responsible for factor XII deficiency were found in these exons (5-8). In some patients an additional TaqI site in the second intron of the gene was detected. This TaqI site was not detected in control groups with normal factor XII activities (9). We report here a novel mutation termed $11396(\mathrm{G} \rightarrow \mathrm{A})$, a $\mathrm{G}$ to $\mathrm{A}$ transition at nucleotide position 11396 of the gene. Blood samples from 12 patients whose low factor XII activity was detected by chance during presurgery

Table 1. Genotypes and factor XII parameters for factor XII deficient patients

\begin{tabular}{llllll}
\hline Patient & $11396(\mathrm{G} \rightarrow \mathrm{A})$ & FXII:C & F XII: Ag & PTT (s) \\
\hline 54 & $*$ & $+/-$ & $5 \%$ & $<1 \%$ & n. d. \\
63 & $*$ & +- & $2.8 \%$ & $<1 \%$ & 69.8 \\
88 & $*$ & $+/-$ & $<1 \%$ & n.d. & 65.8 \\
90 & $*$ & $-1-$ & $<1 \%$ & n.d. & 121.9 \\
97 & $\S$ & $+1+$ & $46 \%$ & $44 \%$ & 27.2 \\
98 & $* \S$ & $+1-$ & $2.2 \%$ & $<5 \%$ & 43.9 \\
99 & $\S$ & $+1+$ & $22 \%$ & $23 \%$ & 33.5 \\
100 & $\S$ & $+/-$ & $16 \%$ & $23 \%$ & 39.6 \\
101 & $\S$ & $+1-$ & $20 \%$ & $26 \%$ & 32.8 \\
102 & $\S$ & $+1-$ & $23 \%$ & $25 \%$ & 33.7 \\
103 & $\S$ & $+/-$ & $17 \%$ & $25 \%$ & 33.8 \\
104 & $\S$ & $+/+$ & $23 \%$ & $28 \%$ & 33.9 \\
\hline
\end{tabular}

*denotes unrelated patients from our group of 12 independent cases; $\S$ denotes members of the family described in the pedigree (Fig. 2). Wild type sequence $(+)$, mutant sequence $(-)$, FXII:C $=$ factor XII activity, F XII:AG $=$ factor XII antigen level, PTT $=$ partial thromboplastin time, n.d. $=$ not determined.

Table 2. Primer sequences for analysis of exons 13 and 14 as depicted in Figure 1

\begin{tabular}{ll}
\hline JM32: & 5'-AGGATCTGACGGTGGTGCTC \\
EX12F: & 5'-TCCGAGACCACGCTCTGCCAG \\
EX13F: & 5'-TCCCCGGCATGCTCTGCGCAG \\
EX14R2: & 5'-TGGGGGAATGGGACACAATCTTG \\
JM35: & 5'-TTGAGTTCCTGCGCCATCC \\
\hline
\end{tabular}

screening were collected. Genomic DNA was prepared and analysed by PCR and direct sequencing for mutations as described (10). RNA preparation and cDNA synthesis with subsequent PCR was performed according to Schloesser et al. (11). Total RNA from peripheral blood lymphocytes was reverse transcribed by exon 14 specific primer and amplified in two stages with primers located in exons 11,12 and 14 (Tables 1 and 2). For both genomic and cDNA templates PCR conditions included pairs of primers $(10 \mathrm{pmol})$ in a total

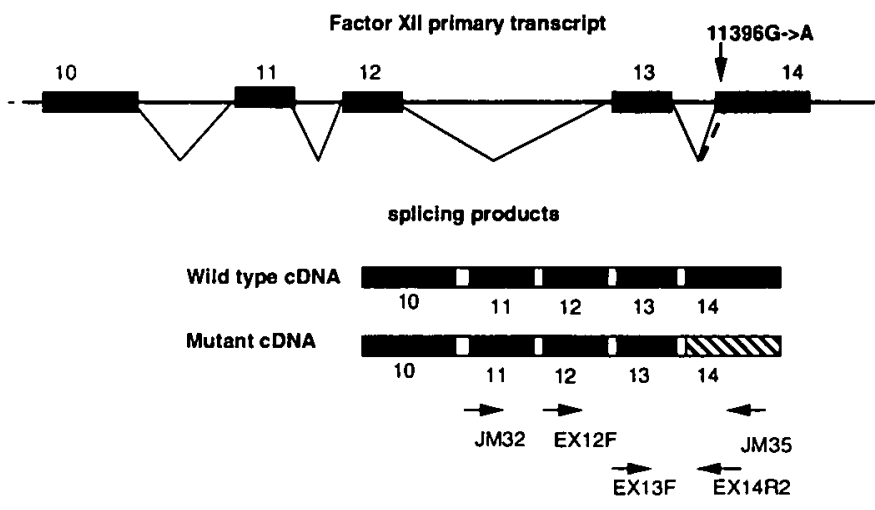

Figure 1. Factor XII primary transcripts and splicing products as derived from the analysis of transcripts. The hatched bar symbolises the truncated exon 14 sequences and the aberrant reading frame.

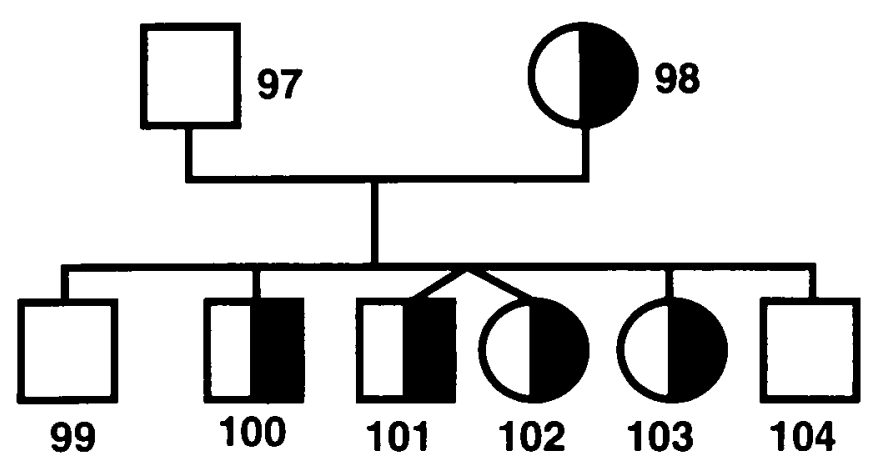

Figure 2. Family pedigree for patients 97-104. The mutant allele was detected in the patients with half filled squares and circles, respectively. Factor XII parameters are listed in Table 1. 


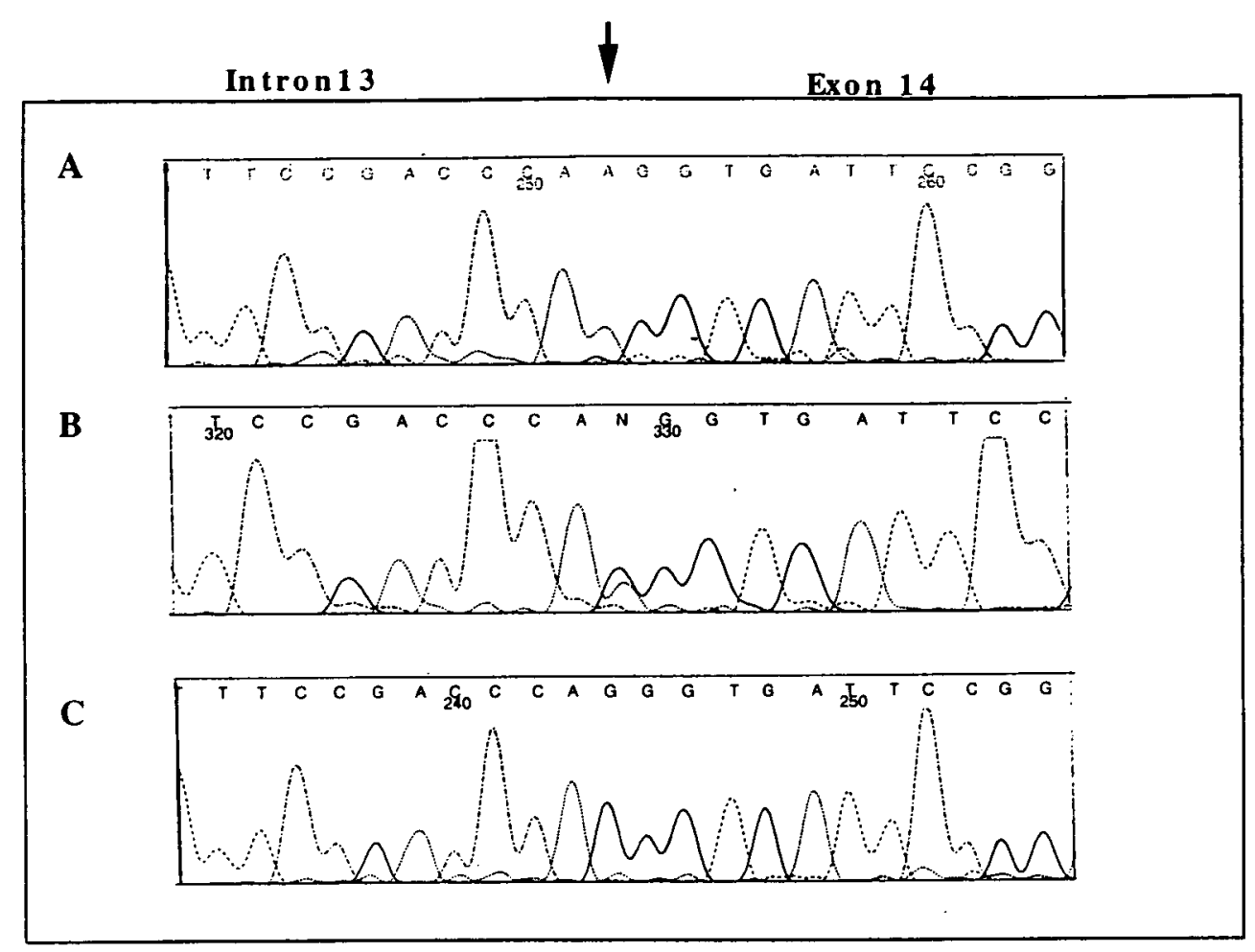

Figure. 3. Fluorescence sequence analysis of PCR products referring to genomic DNA from patients homozygous for 11396 (G $\rightarrow A$ ) (panel $A$ ), heterozygous (panel B) and homozygous for the wild type allele (panel C). The arrow indicates the position of the mutation.

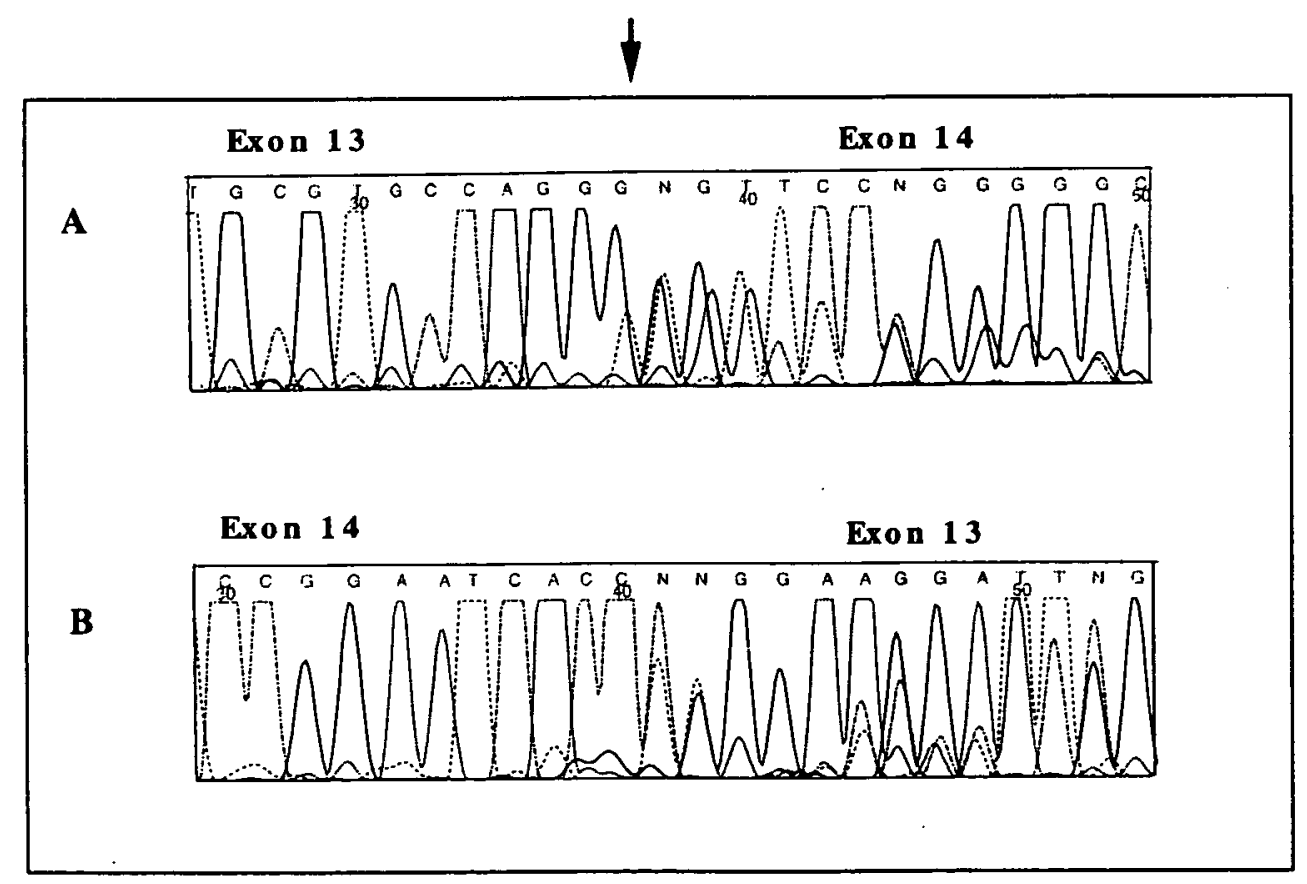

Figure 4. Fluorescence sequence analysis of the PCR product derived from reverse transcribed RNA of patient 63 heterozygous for the mutation 11396 (G $\rightarrow A$ ). In panels $\mathrm{A}$ and $\mathrm{B}$ the forward and the reverse sequence is depicted, respectively. The arrow indicates the border between exon 13 and 14 sequences for both transcripts which are superimposed.

volume of $0.1 \mathrm{ml}$ with $0.1 \mathrm{U}$ of Taq polymerase, $5 \%$ DMSO and buffer components as recommended by the manufacturer (Stehelin, Basel, Switzerland). The PCR temperature profile was repeated for 35 cycles; annealing at $60^{\circ} \mathrm{C}$ for $1 \mathrm{~min}$, extension at $72^{\circ} \mathrm{C}$ for $90 \mathrm{~s}$ and denaturation at $94^{\circ} \mathrm{C}$ for $1 \mathrm{~min}$. Factor XII parameters were determined as described by Braulke 
et al. (12). Direct automated fluorescence sequencing of PCR products from 12 unrelated patients with factor XII deficiency revealed the novel mutation $11396(\mathrm{G} \rightarrow \mathrm{A})$ in the splice acceptor site of exon 14 (11). The gene frequency is $p=0.25$ with six out of 24 chromosomes analysed (Table 1). Patients carrying this mutation had no cross-reacting material (CRMnegative), i.e no factor XII protein and no enzymatic activity. We did not detect this mutation in the DNA of 74 unrelated individuals.

Patient 54 is 26 years of age and his low factor XII activity was detected during pre-surgery screening. His mother had venous thrombotic complications. His paternal grandfather had a heart infarction. Patient 63 is 60 years of age and suffered from two heart infarctions. His low factor XII status was discovered when he attended a hospital for therapy of his hemorrhagic ulcus. Patient 90 is a 65 year old mother of four children whose factor XII deficiency was disclosed by chance. The factor XII deficiency of patient 100 , a 12 year old boy, was discovered while he was staying in a hospital.

The mutation is located at nucleotide position 11396 of the gene (4), referring to the 3 '-splice acceptor site of exon 14 (Fig. 3). The sequence ccgacccagGGTGATT is changed to ccgacccaaGGTGATT (lower case: intronic, upper case: exonic sequences, bold face: acceptor site), thereby moving the acceptor site one nucleotide downstream. This can be demonstrated by analysis of the transcripts, as this sequence alteration should affect the processing of the primary gene transcripts (Figs 1 and 4). The aberrant splicing was demonstrated for patients 54 and 63 which were compound heterozygotes for $11396(\mathrm{G} \rightarrow \mathrm{A})$ and for patient 90 which is homozygous. The corresponding ectopic transcripts were detected by reverse transcription and subsequent PCR (10). Direct sequencing of the PCR products demonstrated that exons 13 and 14 splicing products are lacking one nucleotide, as exon 13 is fused to a novel site in exon 14 one nucleotide downstream to the native position. This novel splice site can be explained on the basis of consensus values as described by Krawczak et al. (13). These authors consider the usage of a given sequence as a splice site depending on their similarity to a given consensus sequence. For splice site mutations two different mechanisms are discussed. Either the exon following the mutation is skipped or a cryptic splice site is used (13). As in the case of 11396 $(\mathrm{G} \rightarrow \mathrm{A})$ the affected site is located at the last exon, and exon skipping would not function. Therefore, in this case, cryptic splice site usage is employed with the consequence that the reading frame in exon 14 is shifted one nucleotide downstream. The derived protein would lack the functionally important serine at position 544, all other amino acids encoded by exon 14 , and the functionally important translational stop codon. As both compound heterozygous patients 54 and 63 and the homozygous patient 90 , lack any immunological reactive protein (Table 1), this novel mutated allele results in a detectable transcript but unstable protein. Mendelian inheritance for this mutation was demonstrated in the family of patient 98. This patient is heterozygous for $11396(\mathrm{G} \rightarrow \mathrm{A})$ and four of her six children inherited this mutant allele from her. These family members carrying this allele have both a reduced factor XII activity and antigen (Table 1 and Fig. 2). There are at least two more mutant factor XII alleles in this family of unknown nature which we are currently trying to characterise. One possible candidate could be the Taql allele described by Bernadi et al. (9). However, for this allele it is still unclear if it is a mere polymorphic marker or a true gene lesion. For the novel mutation $11396(\mathrm{G} \rightarrow \mathrm{A})$ we can definitely postulate that it has a causative effect on the phenotype, as we could detect a truncated transcript resulting in unstable protein. Currently we are collecting blood samples from patients with myocardial infarction and women with recurrent habitual abortions, in order to investigate the frequency of this mutated allele in these populations.

\section{ACKNOWLEDGEMENTS}

We thank Stefanie Schwager for excellent technical assistance. We are grateful to the 'Wilhelm-Sander-Stiftung' for grant No. 94.021.1.

\section{REFERENCES}

1. Fuhrer,G., Gallimore,M.J., Heller,W. and Hoffmeister,H.E. (1990) Blut 61: $258-266$.

2. Goodnough,L.T., Saito,M. and Radnoff,O.D. (1983) Medicine (Baltimore) 62: 248.

3. Mannhalter,C., Fischer,M., Hopmeier,P. and Deutsch,E. (1987) Fibrinolysis 1: 259.

4. Cool,D.E. and Macgillivray,R.T.A. (1987) JBC 262: 13662-13673.

5. Kemptner,B., Rueth,S., Epple,I. and Lohse,.P (1993) Beitr Infusionther. Freiburg, Karger 31: 174-178.

6. Wuillemin,W.A., Huber,I., Furlan,M. and Lämmle,B. (1991) Blood 78: 997-1004.

7. Wuillemin,W.A., Furlan,M., Stricker,H. and Lämmle,B. (1992) Thrombosis Haemostasis. 67: 219-225.

8. Myata,T., Kawabata,A.I., Iwanaga,S., Takahashi,I., Aving,B. and Saito,H. (1989) Proc. Natl. Acad. Sci. USA 86: 8319-8222.

9. Bernadi,F., Marchetti,G., Volinia,S., Patracchini,P., Casonato,A., Girolamo,A. and Concon,F. (1988) Hum. Genet. 80: 149-151.

10. Schloesser,M., Arleth,S., Lenz,U., Bertele,R.M. and Reiss,J. (1991) J. Med. Genet. 28: 878-880.

11. Schloesser,M., Slomski,R., Wagner,M., Reiss,J., Berg,L.P., Kakkar,V.V. and Cooper,D. (1990) Mol. Biol. Med. 7: 519.

12. Braulke,I., Pruggmayer,M., Melloh,P., Hinney,B., Köstering,H. and Gunther,E. (1993) Fertility Sterility 59: 98-101.

13. Krawczak,M., Reiss,J. and Cooper,D.N. (1992) Hum. Genet. 90: 41-54. 